\title{
Back Pain, CTCAE 5.0
}

National Cancer Institute

\section{Source}

National Cancer Institute. Back Pain, CT CAE 5.0. NCI Thesaurus. Code C146739.

A disorder characterized by a sensation of marked discomfort in the back region. 